\title{
VIOLENCIA ESTRUCTURAL DE GÉNERO EN LA ARGELIA INDEPENDIENTE: UNA ESTRATEGIA POLITICA
}

\author{
CARMELO PÉREZ BELTRÁN \\ Universidad de Granada
}

\section{SOBRE VIOLENCIA ESTRUCTURAL DE GÉNERO}

El concepto de violencia ha sido definido tanto por la violentología, como por la investigación para la paz (Peace Research), siendo Johan Galtung uno de los más destacados teóricos, quien aboga por utilizar una noción lo más amplia posible de violencia que pueda englobar sus diferentes dimensiones, puesto que los significantes del signo "violencia», como bien afirma José Manuel Martín Morillas $^{1}$, son múltiples, elusivos, ambiguos, ambivalentes e incluso insondables. De esta manera, Galtung afirma que «la violencia está presente cuando los seres humanos se ven influidos de tal manera que sus realizaciones efectivas, somáticas y mentales están por debajo de sus realizaciones potenciales», es decir, cuando existe "distancia entre lo potencial y lo efectivo", "entre aquello que podría haber sido y aquello que realmente es», al igual que todo obstáculo que dificulte la aminoración de dicha distancia ${ }^{2}$.

Una de las principales dimensiones de la violencia es la estructural, llamada también institucional o indirecta, que, contrariamente a la violencia personal, es mucho más compleja y abstracta debido a su imbricación en la estructura social y a la ausencia de actores determinados que ejerzan la acción violenta; es más estática e inmóvil, debido a su amplia prolongación en el tiempo; es más difusa y generalizada, debido a su influencia sobre amplias capas sociales $y$, aunque quizás sea menos impactante o revulsiva, puede causar tanto sufrimiento como cualquier tipo de violencia personal directa.

1. Martín Morillas, José Manuel: Los sentidos de la violencia, Granada, Universidad de Granada, 2003 , pp. 44 y ss.

2. Galtung, Johan: Investigaciones teóricas. Sociedad y culturas contemporáneas, Madrid, Tecnos, 1995, pp. 314 y ss. 
En tanto que sistémica, la violencia estructural genera desigualdades e injusticias, puesto que presupone un acceso diferencial a los recursos y a los beneficios, una marginación en las tomas de decisiones, una descobertura de las necesidades humanas, una degradación de la calidad de vida, y, en definitiva, una traba a la potencialidad efectiva de los seres humanos. Además de cuestiones obvias como la pobreza, el hambre, la mortandad infantil, el analfabetismo, el retraso del sector salud, etc., otra importante dimensión de violencia estructural es la desigualdad basada en el género.

Esta violencia estructural de género está basada en la articulación de un conjunto de instrumentos destinados a la preservación del poder masculino, con el objetivo de reprimir la potencialidad de las mujeres o de reconducir dicha potencialidad hacia determinados ámbitos (la familia, el hogar, la naturaleza), de tal forma que no interfiera en la hegemonía masculina.

Aunque no son concepciones sinónimas, la violencia estructural de género comparte muchas de las características que definen al patriarcado, que ya en los años setenta, Kate Millet definía como una organización social ancestral que se organiza en torno a una doble jerarquía, según la cual el hombre ejerce su dominio sobre la mujer y el adulto sobre el joven, con el fin de monopolizar el poder, evitar la segmentación e impedir la evolución del sistema ${ }^{3}$. Para realizar estos objetivos, el patriarcado se ha basado en dos principios fundamentales: la coerción y la socialización ${ }^{4}$. La coerción patriarcal ejerce su sistema de control por medio de leyes o de normas consuetudinarias sancionadoras que tienen por objetivo la exclusión de las mujeres del espacio público para que éste pueda ser controlado por los individuos susceptibles de poder y prestigio: los varones adultos. En cuanto a la socialización, es sabido que el patriarcado asigna a las mujeres una serie de valores y actitudes, tomados muchas veces del universo simbólico-religioso, sobre los que asienta sus mecanismos, tales como la obediencia, la sumisión, la pasividad, etc. que permite la neutralización de las capacidades sociales del colectivo femenino, sin la posibilidad de plantear algún tipo de disensión ni de contestación.

Personalmente, yo prefiero utilizar el término «violencia estructural de género» porque está más relacionado con ciertas políticas o proyectos socio-económicos actuales, fácilmente identificables, generados y promovidos desde las propias instituciones, con el fin de llevar a la práctica cierto modelo de gestión del Estado, determinado por la desigualdad entre hombres y mujeres y por la exclusión de éstas de los resortes sociales, políticos y económicos del país. El Estado es, sin duda, el principal impulsor o generador de violencia estructural

3. Millet, Kate: Sexual Politics, New York, Doubleday \& Company, 1970. Esta obra, clásica ya del feminismo, ha sido traducida recientemente al español bajo el título de Política sexual, Madrid, Cátedra, 1995.

4. Alicia H. Puleo habla de dos tipos de patriarcado: patriarcado de coerción y patriarcado de consentimiento, que esencialmente designan esta misma realidad. Véase de esta autora, la voz «Patriarcado», en Celia Amorós (dir): 10 palabras clave sobre mujer, Pamplona, Verbo Divino, 1995, pp. 28-37. 
de género, justificando las desigualdades en aras del bien común, la ley y el orden, la patria, el desarrollo de la nación, la cultura, la religión, etc.

\section{VIOLENCIA ESTRUCTURAL DE GÉNERO EN ARGELIA: UNA HIPÓTESIS DE PARTIDA}

Este trabajo parte de la hipótesis de que el estado argelino, prácticamente desde la independencia del país en 1962, ha promocionado un desarrollo desigual, con el objeto de reprimir la potencialidad de las mujeres, generando violencia estructural de género. Los instrumentos de los que se ha valido el poder político para conseguir dichos objetivos han sido el control de la religión, la ley, la moral, la sexualidad y del aparato institucional, de tal forma que este sistema ha conseguido excluir a las mujeres de los enclaves económico, político y cultural, y orientar su potencial hacia el ámbito privado, priorizando el rol de madre y esposa, infravalorando el rol de ciudadanas y promocionando una ideología reduccionista y misógina.

Hablar de mujeres argelinas es hablar de una doble lucha: la lucha por la independencia y la construcción de un país y la lucha por el reconocimiento de los derechos de las mujeres. En ambos casos estamos ante un proceso en el que las mujeres no han salido bien paradas, puesto que ni ocupan el lugar que les corresponde en la sociedad ni han logrado la igualdad de género que es de justicia. Las razones que justifican este estado de cosas son muchas y complejas, ya que inciden múltiples factores, pero no cabe duda de que en gran parte es debido a una minuciosa planificación institucional del poder político, que articula todo un entramado de instrumentos que promocionan los valores patriarcales, la mística de la masculinidad y la represión de la potencialidad de las mujeres.

Se ha escrito muchísimo sobre la importante participación de las argelinas durante la Guerra de Liberación Nacional que conduciría al país a su independencia. Y es innegable que su aportación fue muy importante, pero también es cierto que el $F L N$, a través de diferentes recursos propagandísticos, ha utilizado estas circunstancias de forma parcial y demagógica con el fin de limitar la emancipación de las mujeres. Como bien ha demostrado la afamada investigadora Djamila Amrane, las mujeres no sólo fueron aceptadas con reticencias en la guerra, sino que se vieron excluidas de los puestos de responsabilidad, tanto de la vertiente civil como militar del $F L N^{5}$. De este modo, las argelinas desempeñaron una función de apoyo a sus "hermanos», es decir, se manifestaron masivamente, apoyaron las huelgas, recolectaron dinero, alimentos y medicinas, sirvieron de guías, cuidaron de la salud y de la alimentación de sus camaradas, etc., pero, contrariamente a la propaganda oficial, fueron excepcionales las que cogieron las armas.

5. De esta autora, véase principalmente: «La femme algérienne et la Guerre de Libération Nationale 1964-1962", en Actes des Journées d'étude et de reflexion sur les femmes algériennes, Orán, CDSH, 1980, pp. 201-223; «Aproche stadistique de la participation de la femme algérienne à la Guerre de Libération Nationale 1964-1962", Majallat al-Tarikh, (1981), pp. 75-92; Les femmes algériennes dans la Guerre, Paris, Plon, 1991. 
Lo que sí es cierto es que durante los años de guerra, debido principalmente a necesidades vitales (alimentación, localización de familiares, sepelios, asistencia a juicios, visita a presos/as, etc.), se produjo cierta evolución de las mentalidades, usos y costumbres que favoreció el acceso de la población femenina a la vida pública, y una mayor participación de ésta en la sociedad y en la Historia.

Pero lo realmente grave para las mujeres fue la estrategia que pone en marcha el estado tras alcanzar la independencia en 1962, con la intención de clausurar esta nueva dinámica social y de reconducir a las mujeres al espacio privado. Este fenómeno de "reconducción femenina", inaugurado por el régimen argelino bajo la tutela del Ejército, cumple varios objetivos: en primer lugar, supone una estrategia de control social de la mitad de la población; en segundo lugar, evita el desorden simbólico-religioso (fitna) que puede suponer la presencia de las mujeres en el espacio público; por último, legitima la política de represión de las potencialidad efectiva de las mujeres.

De este modo, el gobierno argelino pondrá en marcha un proyecto de desarrollo global, determinado por la violencia estructural de género, que delimitará escrupulosamente el espacio asignado al potencial femenino, que no será otro que el de la familia y la privacidad del hogar, ignorando de esta forma el papel social y económico que deberían jugar las mujeres en la construcción del país.

\section{VIOLENCIA ESTRUCTURAL DE GÉNERO EN EL SISTEMA EDUCATIVO ARGELINO}

Es indudable que el régimen argelino ha invertido importantes energías y recursos en educación ${ }^{6}$ para poder extender la formación de forma generalizada, ya que durante época colonial Argelia careció de una verdadera política educativa, de tal forma que al llegar a la independencia la mayor parte de la población era analfabeta. Indudablemente esto será un handicap para toda la población pero, no cabe duda, ha afectado de forma mucho más directa a las mujeres, como bien demuestran las tasas de alfabetización en la actualidad, puesto que, según datos facilitados por el PNUD referentes al año 2001, sólo un $58,3 \%$ de la población femenina adulta (mayor de 15 años) puede considerarse alfabetizada, índice éste que asciende hasta el $77,1 \%$ para los hombres ${ }^{7}$. Las causas que justifican este desfase entre ambos sexos vuelven a ser multiformes y complejas (económicas, sociales, culturales, ideológicas...), pero qué duda cabe que en gran parte es responsabilidad de la política educativa del estado y de las prioridades que éste se marque, ya que cuando un régimen tiene dificultades para desarrollar una política determinada suele dar prioridad a aquellos elementos que les son más inmediatos o que considera más útiles para llevar a la práctica su proyecto socio-económico; en este caso, los hombres, mientras

\footnotetext{
6. Véase, por ejemplo, Pérez Beltrán, Carmelo: «El sistema educativo de la Argelia independiente: estructura y problemáticas", Al Andalus-Magreb, 2 (1994), pp. 223-243.

7. Véase http://www.undp.org/hdr2001/spanish/
} 
que la potencialidad de las mujeres vuelve a ser relegada en espera de tiempos mejores.

Lo cierto es que este elevado índice de analfabetismo ha tenido efectos perjudiciales e inmediatos entre la población femenina, que, debido a ello, sigue reproduciendo planteamientos tradicionales y patriarcales, los cuales, mixturados con unos valores simbólico-religiosos alienantes, facilita la exclusión de las mujeres de la esfera pública.

Pero ésta no es la única traba que aflige al colectivo femenino en materia educativa. Otro problema importante es el absentismo y el abandono escolar ${ }^{8}$. Si bien es cierto que la práctica totalidad de las niñas se encuentran matriculadas en los niveles elementales de la enseñanza primaria, también lo es que a partir de los inicios de la adolescencia la presencia de las niñas en las aulas desciende de una manera enormemente significativa, siendo éste un problema endémico en las zonas más retrasadas del interior y del sur, en donde las infraestructuras, los medios socioeconómicos y el desarrollo cultural son menores. Y lo más grave de este problema es que no desaparece con los años sino que, como toda violencia estructural, se prolonga indefinidamente en el tiempo. Una de las causas que pueden justificar este fenómeno hay que buscarla en la instrumentalización que el régimen argelino ha hecho del islam, mediante el cual se ha fomentado directa e indirectamente una serie de valores reaccionarios que tienen que ver más con su estrategia social, económica y cultural (violencia estructural de género) que con la propia religión. Según dichos valores, la finalidad de la educación femenina no es otra que la obtención de rudimentos de escritura y lectura que faciliten las tareas domésticas, la relación con su esposo y la educación de sus hijos; por lo tanto, una vez que aparecen los caracteres sexuales secundarios de la adolescencia (11-12 años), es más apropiado que las jóvenes eludan el contacto con el exterior, eviten toda relación con el sexo opuesto, custodien su virginidad, velen por el honor familiar, etc.

En este contexto de manipulación simbólico-religiosa con el objetivo de legitimar programas políticos, podríamos ubicar la constante censura a la que se ha visto sometida la práctica del deporte femenino en las escuelas e institutos, especialmente virulenta en los años ochenta ${ }^{9}$, cuando el islamismo se erige en custodio del control social, ya que la indumentaria y la exhibición del cuerpo no son consideradas apropiadas para la "naturaleza femenina». Este debate sale a la palestra con ocasión de la promulgación de la Ley 89-03 de febrero de 1989 relativa a la Organización del Deporte, que, aunque estuvo precedida de innumerables controversias ideológicas, finalmente no formula discriminación alguna de

8. Véase Pérez Beltrán, Carmelo: Mujeres argelinas en lucha por las libertades democráticas, Granada, Universidad (Col. Feminae), 1997, pp. 189-190. Véase también: TALAHITE-HaKIKI, Fatiha: «Scolarisation et formation des filles en Algérie: préparation au salariat ou production de menagères modernes?", Annuaire de l'Afrique du Nord, XIX (1980), pp. 289-319; Nouredine, Saadj: La femme et la loi en Algérie, Casablanca, Le Fennec, 1991, p. 109.

9. Véase «Sport féminin. Regression continue», Horizons, 1276 (1 de noviembre de 1989), p. 10. 
sexo, pero lo cierto es que en la práctica, el deporte se convirtió en una materia optativa para las alumnas.

Otros ámbitos educativos que han estado determinados por la violencia estructural de género, con la finalidad de minimizar el potencial femenino, son la formación profesional y los contenidos de los manuales de enseñanza. Respecto a la formación profesional, hay que señalar el significativo desfase cuantitativo entre alumnos y alumnas dentro de este nivel de enseñanza media y secundaria que es el más directamente relacionado con las necesidades laborales del país. Por poner un ejemplo, hacia el año 1985, el porcentaje de alumnas matriculadas en los centros de formación profesional no superaba $25 \%$ del total, mientras que el de alumnos se elevaba a más del 75\% ${ }^{10}$. Y esto a pesar de que el gobierno argelino ha dedicado una especial atención a este tipo de educación, con vistas a la gestión del mercado de trabajo y al desarrollo económico del país, pero resulta obvio que su interés en la introducción del colectivo femenino ha sido muy escaso, sin duda porque escaso era su empeño por la futura incorporación de las mujeres dentro del ámbito del trabajo.

En cuanto a los contenidos de los libros de texto, existen varios estudios que demuestran que los manuales destinados a la formación de niños y jóvenes transfieren valores tradicionales que desvalorizan la capacidad de las mujeres y legitiman la discriminación y la subordinación de éstas. De este modo, los libros de texto asignan a los personajes femeninos (ya de por sí menos frecuentes que los masculinos) los roles tradicionales de madre y ama de casa y las cualidades más relacionadas con el sentimiento, como la dulzura, la emoción, el cariño, etc. Por el contrario, los personajes masculinos son mucho más dinámicos, desempeñan múltiples funciones y sus cualidades son más racionales e intelectuales. En definitiva, los libros de texto, lejos de velar por una relación igualitaria de género, vehiculan unas estructuras mentales anquilosadas y reduccionistas que legitiman la represión de la potencialidad efectiva de las mujeres.

Y lo más grave del asunto es que la grave crisis del sistema educativo argelino ha sido frecuentemente achacado a la excesiva presencia de maestras y profesoras $^{11}$, como si ellas fueran las causantes de la debilidad, la falta de calidad y los defectos de la educación en Argelia, como ocurrió a finales de los años ochenta, cuando se desplegó toda una campaña de desprestigio de las profesionales de la educación, que según Zineb Guenoudj tenía dos objetivos: frenar la participación de las mujeres en la vida activa y desvirtuar el lugar estratégico del que disfrutan las maestras en el sistema escolar y en la sociedad ${ }^{12}$. Sólo que como la cuestión era tan grave, se identificó a los islamistas como los únicos instigadores de dicha campaña, cuando en realidad el régimen hacía al menos una

10. Véase Khodja, Souad: A comme Algériennes. Essai de sociologie politique de la famille, Argel, ENAL, 1991, p. 96.

11. A finales de los años ochenta, las maestras representaban un $42 \%$ del total de los profesionales de la enseñanza primaria y el $29 \%$ de los profesores de secundaria. Véase Pérez BeLtrán, Carmelo: Mujeres argelinas... op.cit., pp. 184-186.

12. Guenoudj, Zineb: «Les femmes et l'enseignement», El-Moudjahid, 3 de octubre de 1989, p. 13. 
década que había confiado a esta tendencia, presente en sus propias estructuras, el control social y, especialmente, la gestión educativa. Además, en un sistema de corte autoritario-militar como el argelino, difícilmente se podría orquestar una campaña de semejante repercusión, con eco incluso en la prensa escrita, sin contar con beneplácito o, al menos, la complicidad del poder político.

\section{VIOLENCIA ESTRUCTURAL DE GÉNERO EN EL ÁMBITO LABORAL}

Posiblemente sea el ámbito laboral en el que se ha plasmado de forma más evidente la represión de la potencialidad de las mujeres por parte del estado, tanto desde el punto de vista ideológico como en el porcentaje de población activa.

Ideológicamente, las constantes limitaciones a la introducción de las mujeres en el mercado laboral han estado legitimadas por diversos documentos oficiales, de los cuales posiblemente el más elaborado sea la Carta Nacional de 1976, que afirmaba abiertamente que "la integración de la mujer argelina en los circuitos de producción debe tener en cuenta una serie de obligaciones inherentes a su rol de madre de familia y de esposa en la construcción y consolidación del hogar familiar, que forma la célula constructiva de la nación $»^{13}$. Es decir, el estado está transmitiendo la idea de que las mujeres tienen una obligación principal, inherente a su «naturaleza» (buena esposa e inmejorable madre) y una facultad secundaria y accidental, supeditada a aquella, como es el acceso al trabajo. En esa misma tónica de legitimación de la desigualdad, la Carta Nacional estipula una actividad económica femenina acorde con "sus aptitudes y competencias», lo cual supone establecer oficialmente una división sexual del trabajo, puesto que se concibe que existen ciertas profesiones «aptas y de la competencia» de las mujeres y otras que no lo son.

No sólo la Carta Nacional legitima ideológicamente la limitación de la potencialidad laboral de las mujeres. No podemos olvidar que, según el artículo 37 del Código de la Familia vigente desde 1984, el marido tiene la obligación legal de mantener a la esposa, con lo cual el salario de la mujer siempre será considerado como una ayuda complementaria, secundaria, accidental, a la economía familiar ${ }^{14}$. De este artículo se deriva un doble perjuicio para las argelinas: por un lado la dependencia económica de las mujeres y por otro lado, como contrapartida, la obediencia que la esposa debe a su marido en calidad de cabeza de familia, según se desprende del artículo $39^{15}$.

13. "Carta Nazionale Algerina (2-6-1976)», Oriente Moderno, LVI, 5-6 (mayo-junio 1976), p. 187.

14. «El marido está obligado a mantener a su esposa en la medida de sus posibilidades, salvo cuando se confirma que ésta incumple su débito conyugal (nushuz)...». Véase Pérez Beltrán, Carmelo: «El Código argelino de la familia: estudio introductorio y traducción», en Carmelo Pérez Beltrán y Caridad Ruiz de Almodóvar (eds.): El Magreb. Coordenadas socio-culturales, Granada, Adhara, 1995, pp. 375-411. El art. 37 se encuentra en la p. 390.

15. "La esposa está obligada a obedecer a su marido y tenerlo en consideración en calidad de jefe de familia...», Ibíd., p. 390. 


\begin{tabular}{|c|c|c|c|c|c|c|}
\hline \multicolumn{7}{|c|}{ EVOLUCIÓN DEL TRABAJO FEMENINO $1977-1997$} \\
\hline \multirow{2}{*}{ Población activa femenina (\%) } & 1977 & 1982 & 1985 & 1989 & 1995 & 1997 \\
\cline { 2 - 8 } & 6 & 7 & 8 & 8 & 14 & 16,7 \\
\hline
\end{tabular}

Los datos estadísticos de la tabla adjunta ${ }^{16}$ ilustran perfectamente las pautas que el gobierno ha mantenido en materia de trabajo femenino, es decir, planificar un desarrollo económico desigual, contando con la población activa masculina, casi en exclusividad. En base a los datos señalados, existen dos características principales que determinan a la población activa femenina: su escasísima representación y el inmovilismo a lo largo del tiempo, propio de la violencia estructural. De esta forma, en los años setenta y ochenta del pasado siglo XX, el porcentaje de población activa femenina oscilaba entre el 6 y el $8 \%$, lo cual es especialmente grave si tenemos en cuenta que fue a lo largo de estas décadas cuando se llevaron a cabo los distintos planes de desarrollo industrial ${ }^{17}$ y la llamada revolución agraria, a partir de 1971. Por lo tanto, hubiera sido de esperar que durante este tiempo se hubiese producido una importante introducción de las mujeres en el ámbito laboral, cuestión ésta que nunca se produjo. Además de esto, hay que señalar que en la actualidad, Argelia es uno de los países de todo el Mundo Árabe con índices más bajos de población activa femenina $(16,7 \%)$, muy alejados, en todo caso, de sus vecinos magrebíes, ya que según datos aportados por la OIT, Túnez contaba en 1997 con un 23,9\% de población activa femenina y Marruecos con un $27,1 \%$ en la misma fecha ${ }^{18}$.

Como se deja entrever, la década de los noventa del siglo XX ha sido más generosa para las argelinas que desean acceder a un puesto de trabajo, aunque, según algunos especialistas, no hay que dejarse llevar por el optimismo, puesto que la gran mayoría de ellas tiene una situación híbrida entre el paro y el status de asalariada, ya que o bien desempeñan unos puestos denominados «empleos de solidaridad» reservados a los demandantes de empleo o bien realizan una serie de actividades muy precarias.

Debido a la falta de promoción, o mejor dicho, a la política de limitación llevada a cabo por el gobierno argelino a lo largo de décadas, existe una serie de características propias del trabajo femenino en este país magrebí, de las cuales

16. Los datos de esta tabla están tomados de las siguientes fuentes: el de 1977, de KHodjA, Souad: Les algériennes du quotidien, Argel, ENAL, 1985, p. 74; el de 1982 de HAmmûDA, N.D.: "Al-Nashât al-niswî: mu'ashshir min mu'ashshirât al-tahawwulât al-idjtimâ'iyya al-iqtisâdiyya", Ihsâ'iyyât, 3 (1984), p. 37; el de 1985 de Khodja, Souad: A comme..., op. cit., p. 132; el de 1989, de NouredINE, Saadj: La femme..., op. cit., pp. 91-92 y 99; el de 1995, de GACEMI, Baya: «Illusions persues et espoirs des femmes", Le Monde Diplomatique, (octubre de 1997), p. 1; y el de 1997, de OIT: Informe sobre el empleo en el mundo, 1998.

17. Un plan trienal de 1967 a 1969 y dos planes cuatrienales: de 1970 a 1973 y de 1974 a 1977 . Véase Benhouria, T: L'économie de l'Algérie, Paris, Maspero, 1980, especialmente pp. 255-296.

18. Población económicamente activa: todas las personas de 10 años o más que aportan su trabajo para la producción de bienes y servicios durante un determinado periodo de tiempo de referencia. Informe sobre el empleo en el mundo, OIT, 1998, p. 267. 
podríamos destacar tres: el carácter urbano, la concentración en una sola rama de actividad y la juventud de las trabajadoras.

Respecto al primer punto señalado, hay que apuntar que en los años ochenta del siglo XX, más del $85 \%$ del total de mujeres ocupadas ${ }^{19}$ desempeñaban su trabajo en medio urbano y menos del $15 \%$ en medio rural, lo cual es consecuencia de la exclusión de las mujeres de los planes de desarrollo que puso en marcha el gobierno desde inicios de los años setenta. Además de esto, existen otros motivos que ayudan a explicar este fenómeno, como es el mayor anclaje de las estructuras patriarcales y de las ideas conservadoras en el medio rural y la consideración del trabajo realizado por las mujeres rurales como «ayuda familiar»y, por lo tanto, no computado como población activa.

Por otro lado, la consideración de las ramas de actividad económica nos demuestra que los planteamientos expresados en los documentos ideológicos del régimen, de los que anteriormente he hablado, se han llevado a la práctica, estableciéndose una clara división sexual del trabajo, según la cual los hombres ocupan puestos de trabajo relacionados con la agricultura, la construcción o la industria, mientras que las mujeres están concentradas en una rama principal: la administración y servicios a la colectividad (el $75 \%$ en 1985), seguido en muy segundo puesto por la industria ligera o de transformación $(12 \%$ en la misma fecha $)^{20}$. La exclusión de las trabajadoras de la industria, especialmente de la pesada, es un hecho muy significativo, teniendo en cuenta que el Estado ha dedicado importantes recursos a este sector clave de la economía argelina que, por otro lado, requiere de la utilización de grandes recursos tecnológicos y científicos y en el cual las mujeres no han sido implicadas por estrategias de empleo, puesto que el paro masculino es extremadamente elevado, y por la falta de formación de éstas en las disciplinas científicas y tecnológicas.

Por último, la consideración del factor «edad» vuelve a confirmar que el trabajo de las mujeres es considerado un factor secundario y accidental, subordinado a un rol principal que es el de esposa y madre. De esta forma, es muy significativo que el mayor número de trabajadoras tenga una edad inferior a 30 años $^{21}$, cuando aún no ha aparecido el status "pseudo transcendental» de casada, o en todo caso, aún se carece de hijos. Por lo tanto, a partir de la edad señalada, que se corresponde con la época conyugal y de la maternidad, las trabajadoras abandonan sus puestos para retomar los roles tradicionales, que según el propio estado, deben ser los prioritarios para ellas, puesto que madre y trabajadora parecen ser dos funciones incompatibles en la sociedad argelina.

Como resultado de la violencia estructural de género en el ámbito laboral, la sociedad argelina mantiene una percepción negativa del trabajo de las mujeres,

19. Dato tomado de Abrous, Dahbia: L'Honneur face au travail des femmes en Algérie, Paris, L'Harmattan, 1989, pp. 55 y 217. Se refiere al año 1982.

20. Porcentajes tomados de KHodja, Souad: A comme..., op. cit., p. 133.

21. Como ejemplo, podemos señalar que en el año 1982, el 31,10\% de la población femenina ocupada se encontraba en una franja de edad que oscilaba entre 20 y 24 años. Dato tomados de Hammûda, N.D.: "Al-Nashâ al-niswî...», op. cit., p. 40. 
potenciada, sin duda, desde las propias instituciones, puesto que ayudan a la realización de un diseño socioeconómico basado en la represión del potencial femenino. De este modo se produce una inseparable imbricación entre lo político, lo sexual, lo económico y lo moral, de tal forma que el trabajo femenino es percibido como un riesgo potencial de perversión, antesala de la promiscuidad, como un elemento distorsionador de la familia y como una transgresión del espacio. Como bien apunta Dahia Abrous, la introducción de las mujeres en la vida salarial no entraña sistemáticamente un cambio en las relaciones entre los sexos, sino que, al contrario, se produce un fenómeno constante de subversión/ neutralización ${ }^{22}$. Es decir, el trabajo femenino, cualificado o no, es un elemento nuevo que supone un atentado (subversión) contra la estructura social y la familia tradicionales. Por este motivo, unas veces las propias trabajadoras de forma inconsciente y otras veces, su familia, utilizan una serie de medidas compensatorias que tienen por finalidad la «neutralización» de dicha «infracción».

\section{VIOLENCIA ESTRUCTURAL DE GÉNERO EN EL ÁMBITO POLíTICO}

La política es el tercer espacio en el que la actuación del régimen ha estado marcada por una violencia estructural de género. Aunque es cierto que desde la promulgación de la primera Constitución, en 1963, las argelinas han disfrutado de plenos derechos políticos $\mathrm{y}$, por lo tanto, de la facultad de elegir y de ser elegida, la realidad efectiva ha sido muy distinta, ya que las mujeres que logren acceder a las instituciones políticas, ya de por si en número insignificante, cumplirán la función exclusivamente simbólica y testimonial, mil veces instrumentalizada, de un estado pretendidamente moderno y socialista.

Si existe un elemento que sistemáticamente caracterice las diferentes elecciones a las tres instancias representativas del país (Asamblea Popular Comunal: $A P C$; Asamblea Popular de Wilayas: APW y Asamblea Popular Nacional: APN) ha sido la masculinización absoluta de las candidaturas, de tal forma que los hombres copaban más del $90 \%$ del total de las listas ${ }^{23}$. En líneas generales, las mujeres han conocido mejor suerte, al menos desde el punto de vista numérico, en los dos niveles inferiores del sistema político argelino: las $A P C$ y las $A P W$, pero con porcentajes iguales o inferiores al $5 \%$ de electas (elecciones a las $A P W$ de 1974). En lo que respecta al Parlamento, es decir, la $A P N$, el mayor número de diputadas hasta el principio de la guerra civil asciende a 9, entre los años 1977 a 1982, de un total de 295 escaños, lo cual supone un índice de feminización del 3,44\%.

Las causas de esta escasa representatividad femenina son bastante complejas, pero podríamos señalar algunas de ellas:

- La masculinización absoluta de las estructuras del estado. Hasta la reforma constitucional de 1989 los candidatos eran elegidos entre los miembros del

22. Abrous, Dahia: L'Honneur face au travail des femmes en Algérie, Paris, L'Harmattan, 1989. Las conclusiones generales se encuentran en las pp. 195-203.

23. Para conocer los datos exactos de participación, véase Pérez Beltrán, Carmelo: Mujeres argelinas..., op. cit., pp. 253-272. 
FLN, en su doble versión civil o militar, o entre los integrantes de las diferentes Organizaciones de Masas. En cualquier caso, nos encontramos ante un sistema piramidal dominado por los hombres, que no parecen mostrar interés alguno por la promoción política de sus conciudadanas.

- La neutralización de la Unión Nacional de Mujeres Argelinas. Es una organización de masas del FLN concebida para "encauzar» o "socializar» al colectivo femenino dentro del macro-proyecto de sociedad del régimen ${ }^{24}$. Por este motivo, la Unión irá perdiendo progresivamente toda capacidad de lucha reivindicativa o emancipadora que poseía en sus orígenes, para centrar su atención en cuestiones exclusivamente sociales, como la alfabetización, la salud, la maternidad y la infancia.

- La falta de acceso de las mujeres a la vida pública y su reclusión en el espacio privado, sujetas a la ideología patriarcal subyacente. Las candidatas que se presentan a las elecciones cumplen una doble característica: poseen una elevada formación intelectual y desempeñan un trabajo cualificado. Puesto que el número de mujeres que observan esta doble casuística es muy limitado, como hemos apuntado anteriormente, su presencia en el mundo de la política no tiene más remedio que ser escasa e insuficiente.

- La existencia de una legislación discriminatoria. Hasta 1991 las leyes electorales de Argelia permitían el uso del voto delegado o voto por procuración, que podía ser usado de forma abusiva por los miembros masculinos de la familia. Según esta práctica, un hombre podía votar hasta por tres miembros de su familia, los cuales delegaban en él este deber y además podía votar en nombre de su esposa sin necesidad de procuración alguna, simplemente mediante la presentación del Libro de Familia (art. $53^{25}$ ), lo cual se traducía en la confiscación del derecho de voto de las mujeres y en cuotas elevadísimas de abstención femenina. Si bien durante todo el régimen de partido único el voto de las mujeres difícilmente podía influir en el cambio ideológico del país, no ocurre así a partir de la instauración del multipartidismo en 1989. Por este motivo, uno de los principales caballos de batalla de las asociaciones de mujeres durante esta época será, por un lado, reivindicar ante el gobierno el cambio inmediato de la ley y, en segundo lugar, concienciar a la población femenina, aletargada políticamente durante décadas, de la necesidad de votar personal y responsablemente en pro del futuro del país. De este modo, las principales asociaciones de mujeres reunidas en una Coordinación Nacional logrará finalmente la promulgación de una nueva ley electoral en abril de 1991 que preveía un único voto delegado y en octubre del mismo año, el Consejo Constitucional declaraba anticonstitucional el voto de los cónyuges sin necesidad de formalidades.

24. Véase Pérez Beltrán, Carmelo: «La Unión Nacional de Mujeres Argelinas: organización femenina de masas», Al-Andalus-Magreb, V (1997), pp. 295-317.

25. Artículo 53: «Están dispensados de la formalidad de la procuración los cónyuges que pueden justificar, en el momento del voto, su vínculo conyugal mediante la presentación del libro de familia, además de su carnet de elector». Artículo traducido textualmente de NACERA y HAWA: «Les femmes et la loi electorale», Bulletin de l'AITDF, 2 (1990), anexo, pp. 22-23. 
En lo referente al gobierno, veinte años tuvieron que transcurrir desde la independencia para que una mujer pudiera introducirse en esta máxima instancia política, hasta que en 1982 Zuhûr Wanîsî encabezó la Secretaría de Estado del Ministerio de Asuntos Sociales, y desde entonces es cierto que Argelia ha contado con varias ministras, algunas secretarias de estado y algunas otras encargadas de diferentes misiones, aunque la mayoría han ocupado, al igual que suele ocurrir en el resto del mundo, carteras relacionadas con los asuntos sociales, salud o juventud y deportes, es decir, aquellos roles que tradicionalmente se consideran más acordes con las "capacidades» femeninas.

También habría que decir que la mayor participación de las mujeres en las instituciones políticas durante la última década obedece a cierta tendencia de cooptación que surge a partir de 1992, cuando el régimen, tutelado por el ejército, necesita contar con el apoyo de algunos sectores de la sociedad civil, principalmente de las élites intelectuales y de las clases medias urbanas, que comparten con él el miedo por la "amenaza islamista», con el fin de legitimar de alguna forma su proyecto político erradicador y excluyente. Un ejemplo claro lo encontramos en la puesta en marcha del Comité para la Salvación de Argelia, en donde el ejército se apoyó en diferentes sectores compuestos por representantes de asociaciones culturales, de grupos de mujeres, intelectuales, representantes de empresa y sindicatos, etc. con el fin de interrumpir las elecciones legislativas de enero de 1992. Este mismo sector constituyó en noviembre de 1993 el Movimiento por la República con el fin de influir en el ejército y en el Alto Comité de Estado en contra de cualquier diálogo con el FIS. Desde entonces, la imbricación entre sociedad civil y sociedad militar se ha reforzado más que nunca en Argelia.

En el ámbito político, también habría que destacar el dinámico movimiento de mujeres que, a pesar de décadas de rígido control y de diversas estrategias de neutralización por parte del partido-estado, se desarrolla a partir de los años ochenta del siglo XX, paralelamente al surgimiento de una nueva sociedad ci$v^{2} 1^{26}$ íntimamente relacionada con el proceso de transición desde partido único del FLN hacia el multipartidismo, y con el contexto de agitación política, movilidad social y crisis económica que vive Argelia en los años ochenta, y que desembocará finalmente en graves revueltas populares a finales de esta década, duramente reprimidas con intervención militar ${ }^{27}$.

26. Véase Pérez Beltran, Carmelo: «Democracia, sociedad civil y derechos humanos en el Magreb», Nova Africa, 12 (enero 2003), pp. 85-105.

27. Especialmente el desarrollo de la sociedad civil de Argelia está relacionado con la crisis económica, la pauperización de la población y la política de ajuste estructural puesta en marcha en los años ochenta para poder hacer frente a la galopante deuda externa. Este reajuste económico, que se inicia en 1988 con la promulgación de la nueva Ley relativa a la Inversión Privada, se marcaba como principal objetivo la reorganización del sistema económico del país, basado ahora en un mayor protagonismo del sector privado y en la reorientación del papel económico que debía desempeñar el estado. En la práctica, la reducción del déficit público pasaba por la creación de nuevos impuestos o la ampliación de los ya existentes, el aumento de los precios de productos básicos (pan, harina, aceite, azúcar, leche, mantequilla), la reducción de puestos 
El movimiento de mujeres ${ }^{28}$ surge una vez superada la euforia de la primera década y media de independencia y una vez que empieza a ser evidente el proyecto discriminador del gobierno argelino. Sin embargo, sería falsear la realidad si no precisásemos desde un primer momento que el movimiento asociativo de mujeres es una manifestación sumamente plural y heterogénea, en la que confluyen asociaciones moderadas que pretenden armonizar los valores occidentales modernos con otros intrínsecos a su cultura, asociaciones de mujeres islamistas, muy preocupadas por impulsar un islam globalizador acorde con una nueva modernidad ${ }^{29}$, y otras tendencias laicas que pueden ser encuadradas dentro de los movimientos feministas de los países en desarrollo, es decir, grupos que reivindican, ante todo, el respeto de los derechos humanos. Posiblemente sea esta última tendencia la que ha combatido de una manera más clara por una mayor justicia social para las ciudadanas argelinas y por su igualdad jurídica y social, pero lo realmente importante sería alcanzar un marco plural, tolerante y respetuoso, en el que las mujeres pudieran optar libremente por la militancia en una u otra tendencia. Esto repercutiría positivamente en el establecimiento de un sistema democrático, basado en el principio supremo del respeto de los derechos humanos, entre los que se encuentra el derecho a la libertad. Igualmente debemos recordar que, en las sociedades árabes, tanto el ámbito político, como el religioso han sido de dominio exclusivamente masculino y, por consiguiente, tanto las asociaciones laicas de mujeres como las islamistas se traducen en la conquista de nuevos espacios.

La lucha por la igualdad jurídica entre los sexos ha sido la espina dorsal del movimiento asociativo de mujeres en Argelia. Prácticamente desde los primeros años de la independencia, el gobierno argelino mostró un interés especial

de trabajo, la disminución de subvenciones con fondos públicos, despidos en la administración y un drástico recorte de los presupuestos destinados a cuatro sectores claves de la sociedad: la salud, la educación, la vivienda y el empleo. Por lo tanto, las condiciones para que estallaran revueltas sociales en Argelia parecían estar reunidas y así ocurrió, por ejemplo, en octubre de 1988 cuando el gobierno, bajo los auspicios del Fondo Monetario Internacional, anunciaba una nueva subida de precios de los cereales y sus derivados como consecuencia de la retirada de subvenciones estatales.

28. Sobre los orígenes y desarrollo del movimiento asociativo de mujeres en Argelia, véase principalmente: Louis, Marie Victoire: "Les algériennes. La lutte», Les Temps Modernes, 432-433 (julioagosto 1982), pp. 153-154; Peuch, Marie: «Lettre d'Alger», Les Temps Modernes, 418 (mayo 1981), pp. 1889-1901; Pérez Beltrán, Carmelo: «Las asociaciones feministas en Argelia: las mujeres y sus derechos», en Gema Martín Muñoz (coord.): Mujeres, democracia y desarrollo en el Magreb, Madrid, Pablo Iglesias, 1995, pp. 81-88; y «Evolución del movimiento femenino y feminista en Argelia: las mujeres y la política», Estudios de Asia y África, XXXIII, 105 (enero-abril 1998), pp. 75-102.

29. Sobre el pensamiento de las mujeres islamistas véase principalmente: BuCAILLE, Laetitia: "L'engagement islamiste des femmes en Algérie», Maghreb-Machrek, 144 (abril-junio 1994), pp. 105-119; MarTín MuÑoz, Gema: «Fundamentalismo islámico y violencia contra las mujeres. Las razones de un falso debate», en Integrismos, violencia y mujer, Madrid, Pablo Iglesias, 1996, pp. 45 58 y "Mujeres islamistas y sin embargo modernas», en Mercedes del Amo (ed.): El imaginario, la referencia y la diferencia. Siete estudios acerca de la mujer árabe, Granada, Departamento de Estudios Semíticos, 1997, pp. 75-89. 
por promulgar una ley de estatuto personal, al igual que el resto de países árabes, que regulara los asuntos relacionados con la familia: matrimonio, divorcio, filiación, herencia, custodia, etc. Nada menos que veintidós años tardó el régimen en sacar a la luz el texto definitivo, pero en los sucesivos anteproyectos y proyecto que le precedieron se puede constatar perfectamente la evolución o más bien «involución» de la ideología del régimen hacia posturas cada vez más discriminatorias y la población femenina; esto suponía, al fin y al cabo, un instrumento más en favor de su proyecto de sociedad, determinada por la violencia estructural de género y la delimitación de los espacios ${ }^{30}$.

Finalmente, en junio de 1984 fue promulgado el Código de la Familia ${ }^{31}$. Como las propias mujeres temían, se trata de una de las legislaciones más arcaizantes de todo el mundo árabe, asentada sobre el violento principio de la dominación masculina y en flagrante contradicción con los principios de igualdad expresados en la Constitución. Atendiendo a las disposiciones de este Código, las mujeres se ven incapacitadas para concluir su propio matrimonio, para unirse a un hombre que no sea musulmán, para actuar libre y autónomamente, para solicitar el divorcio en los mismos casos que el varón, para ser tutoras de sus hijos, para heredar igual porción que el hombre en igualdad de parentesco, etc.

El movimiento feminista argelino ha experimentado múltiples problemas que han ralentizado su acción a favor de la emancipación de las mujeres, y no ha sido tanto cuestión de divergencias en los objetivos o los métodos, como de instrumentalización política e institucional lo que ha imposibilitado el diálogo y la cooperación constructiva. Si bien es cierto que, desde sus orígenes, las asociaciones de mujeres se articulan en torno a líderes carismáticas que marcan en exceso las dinámicas internas de estos grupos, entre otros condicionantes, será a partir de 1992 cuando se produce una importante escisión entre las diversas tendencias, que estuvo alimentada por los intentos de cooptación del régimen con el objetivo de legitimar su política de exclusión y erradicación del islamismo de la escena política. A partir de la fecha señalada, las reivindicaciones feministas pasan a un segundo plano y las energías de las mujeres ${ }^{32}$ se invierten, bien en defender, en estrecha colaboración con el poder político-militar, un proyecto que excluye y persigue al islamismo político de la escena pública (léase el caso de Jalida Mesaudi, Zazi Sadu...), o bien en proponer, cara al régimen, una solución política a la crisis en la que tengan cabida todas las fuerzas políticas del país suficientemente representativas, incluyendo la opción islamista (léase el caso de Salima Guezali, Luisa Hanun, ...). Independientemente de la oportunidad y conveniencia de las diferentes propuestas (aunque personalmente yo

30. Véase principalmente BorRmans, Maurice: Statut personnel et famille au Maghreb de 1940 à nos jours, Paris-La Haya, Mouton, 1977, pp. 521-542 y Pérez Beltrán, Carmelo: Estatuto jurídico de la mujer argelina: matrimonio y divorcio, Granada, Estudios Árabes Contemporáneos, 1991, pp. 97-106.

31. Véase la traducción al español y un estudio preliminar de Pérez Beltrán, Carmelo: «El Código Argelino...», op. cit., pp. 386-411.

32. Véase Pérez BeLtran, Carmelo: «Entre erradicación y diálogo: mujeres argelinas. Crónica 1995», Miscelánea de Estudios Árabes y Hebraicos, 45 (1996), pp. 203-232. 
opte por una solución pacífica, dialogante e integradora), lo que me interesa reseñar en el marco de este estudio es la instrumentalización de las mujeres por un poder político que durante décadas ha planificado un proyecto de exclusión y de subordinación para ellas, negándoles sistemáticamente su condición de ciudadanas de pleno derecho.

\section{A MODO DE CONCLUSIÓN}

Como he intentado expresar hasta aquí, el régimen ha implantado todo un agresivo entramado político, ideológico y económico que tenía por objetivo neutralizar las potencialidades de las mujeres en todos los ámbitos de la vida pública, con el objetivo de asignarle un rol circunscrito al ámbito privado de la familia tradicional argelina. Igualmente, los cimientos ideológicos sobre los que se han asentado las instituciones estatales, tales como la exaltación del patriotismo, el sentido del deber, la omnipresencia del estado, el egregio papel asignado al ejército, y el recurso a una lectura reaccionaria del islam, han propiciado la perpetuación de las estructuras patriarcales marcadas por la neta separación de los espacios, la estrecha limitación de las libertades y la promoción de una socialización basada en sentimientos nacionalistas, fundamentada en sentimientos religiosos e impregnada de valores tradicionales.

Un tipo de violencia estructural de género de semejantes características, como la que se ha señalado a lo largo de este trabajo, ha favorecido y, en cierto modo, legitimado otro tipo de violencia muchas más directa y personal hacia las mujeres que, si bien ha estado presente durante toda la época independien$t^{33}$, se hará mucho más evidente durante los años de guerra civil a partir de 1992, cuando las mujeres serán blanco predilecto de todo tipo de atropellos y de violaciones de derechos humanos.

33. Véase como ejemplo, los testimonios recogidos por M'RABET, Fadela : La femme algérienne suivi de Les Algériennes, Paris, Maspero, 1969. 